\title{
Echocardiographic and angiographic diagnosis of Ebstein's anomaly of the mitral valve
}

\author{
José Luiz Balthazar Jacob, Luis Carlos da Silveira, Domingo Marcolino Braile
}

\begin{abstract}
A rare case of Ebstein's anomaly of the mitral valve was diagnosed by cross sectional echocardiography and angiography.
\end{abstract}

\section{Case report}

A black, female child, aged 2 years and 9 months, had presented with a heart murmur when she was 10 days old. When she was one, frequent dyspnoea developed and by the age of two she was in congestive cardiac failure that improved with drug treatment. She was transferred to our hospital nine months later for catheterisation and surgical treatment.

Physical examination showed poor growth and development. The first heart sound was normal and the second heart sound was accentuated. A pansystolic grade $4 / 6$ murmur was heard at the apex and the third heart sound was audible. There was no oedema and the peripheral pulses were normal.

Electrocardiography showed sinus rhythm and evidence of hypertrophy of both the atria and the right ventricle. The chest $x$ ray showed considerable cardiomegaly. Cross sectional echocardiography showed that the mitral mural leaflet was displaced downwards, and that much of it adhered to the left ventricular wall. It became free below the level of the tricuspid valve (fig 1). The aortic leaflet of
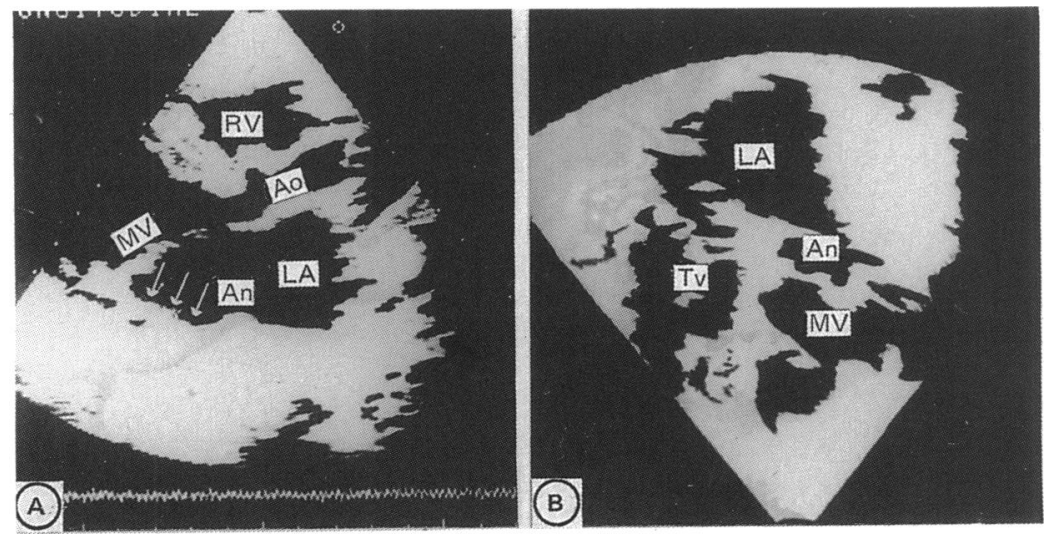

Figure 1 (A) Longitudinal echocardiogram showing the downward displacement of the mitral mural leaflet, much of which adhered to the wall of left ventricle (arrows). Leaflet coaptation of the mitral valve $(M V)$ was displaced downward to the apex of left ventricle. The mitral annulus $(A n)$ was in the normal position. The aorta (Ao), left atrium (LA) and right ventricle (RV) are visible. (B) Apical four chamber echocardiogram showing coaptation of mitral leaflets $(M V)$ below the tricuspid valve (Tv) level. The mitral valve annulus (An) was in the normal position, above the tricuspid valve ( $T v$ ). The left atrium ( $L A$ ) was enlarged. mitral valve also adhered to the left ventricular wall; it too was free below the level of the tricuspid valve.

This echocardiographic image suggests discordant atrioventricular connection with the usual atrial arrangement; however, the great arteries were in the normal position. A Doppler study showed severe mitral regurgitation and catheter studies showed pulmonary artery hypertension. Angiocardiography showed that the pulmonary artery arose from an enlarged right ventricle and systolic function of the left ventricle was reduced. The mitral mural leaflet was displaced downwards into the left ventricle. Much of the mural leaflet adhered to the posterior wall of the left ventricle.

There was coaptation of mitral leaflets in systole below the mitral valve annulus near the apex of the left ventricle, which caused functional atrialisation of the proximal part of this ventricle (fig 2).

There was severe mitral regurgitation with dilatation of the left atrium. Ebstein's anomaly of mitral valve was diagnosed and surgery confirmed the features seen at echocardiography and angiocardiography. The mural leaflet was displaced downward and much of it adhered to the ventricular wall; but the wall thickness of the atrialised part of left ventricle was normal and the trabeculae were normal. The mitral leaflets were dysplastic.

The mitral valve was replaced with a IMCBiomedica bovine pericardium prosthesis. The subsequent course was uneventful.

\section{Discussion}

Ebstein's anomaly of mitral valve is a rare malformation first described by Ruschhaupt $e t$ $a l^{1}$ and later reported by others. ${ }^{23}$ Published reports generally describe the necropsy findings. ${ }^{145}$ The embryological origin is obscure. ${ }^{1}$

Adherence of mitral leaflets to the left ventricular walls, which displaces the level of coaptation of the leaflets towards the apex of the ventricle, is described in other reported cases. ${ }^{236}$ In our patient echocardiography identified the downward displacement of mitral mural leaflet. This suggested a discordant atrioventricular connection with usual atrial arrangement; but a more detailed examination showed the normal attachment of the aortic leaflet of the mitral valve. This is the true diagnostic criterion for Ebstein's anomaly 


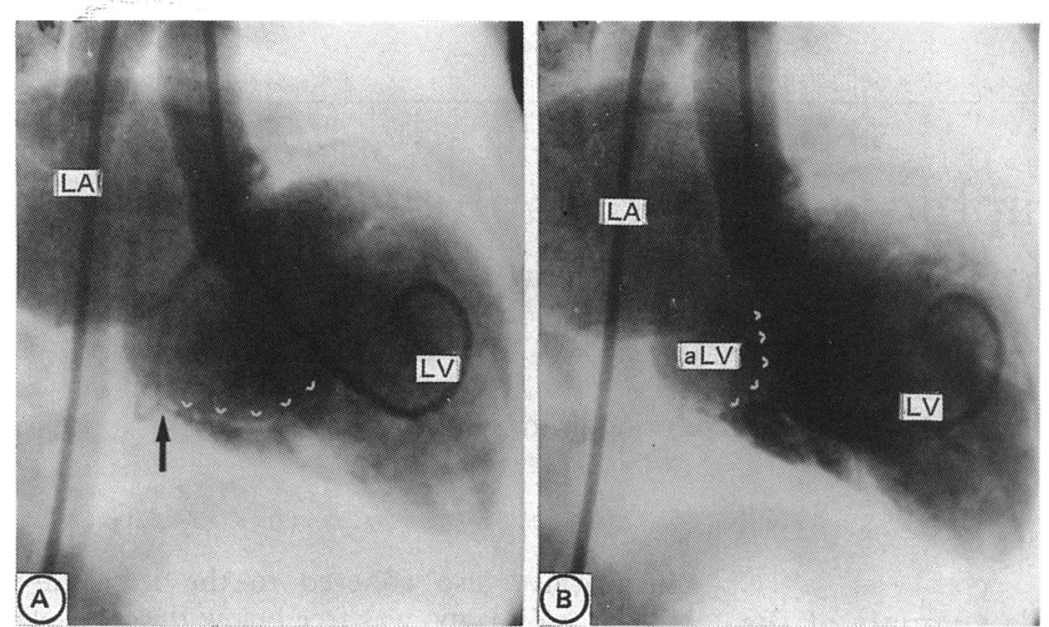

Figure 2 (A) Angiocardiogram of the left ventricle ( $L V$ ) in diastole (right anterior oblique view) showing downward displacement of mitral mural leaflet (black arrow), and its considerable adherence to the ventricular wall (arrowheads).

(B) Angiocardiographic image of the left ventricle ( $L V)$ in systole (right anterior, oblique view) showing downward displacement of mitral leaflet coaptation (arrowheads) and the "atrialised" part of ventricle (aLV). Severe mitral regurgitation and the enlarged left atrium ( $L A)$ are also visible.

of the mitral valve. ${ }^{5}$ Longitudinal and apical four chamber views gave excellent echocardiographic images of the anatomical features of this anomaly.

The angiocardiographic study confirmed the echocardiographic features and showed the displacement of mitral mural leaflet, its adherence to the ventricular wall, and the atrialisation of the proximal part of the left ventricle. Angiocardiography in right anterior oblique view was very useful in the diagnosis of this malformation, and for evaluation of mitral regurgitation.

There are reported cases of only functional atrialisation of the left ventricle, ${ }^{2-6}$ but there is also a report on true anatomical atrialisation of the proximal part of the left ventricle, ${ }^{1}$ in which the atrialised part of the ventricle had thin, smooth walls.

In some cases Ebstein's anomaly of the mitral valve was associated with other malformations, ${ }^{146}$ but in our case it was not. Perhaps this was why our patient survived to the age of 2 years and 9 months, and why surgical treatment was successful.

Surgical repair, which is often used for Ebstein's anomaly of the tricuspid valve, could not be used in our patient, because the leaflets were so dysplastic. ${ }^{7}$

Though Ebstein's anomaly of the mitral valve is rare, it must be considered in patients with congenital mitral regurgitation. It is best detected by cross sectional echocardiography and angiocardiographic study.

1 Ruschhaupt DG, Bharati S, Lev M. Mitral valve malformation of Ebstein type in absence of corrected transposition. Am J Cardiol 1976;38:109-12.

2 Becker AE, Anderson RH. Anomalies of the atrioventricular junction. In: Cardiac pathology: an integrated text and colour atlas. London: Churchill Livingstone, 1983.11 29.

3 Anderson RH, Macartney FJ, Shinebourne EA, Tynan M Mitral valve anomalies and supravalvar mitron Mitral valve anomalies and supravalvar mitral ring. In: Anderson RH, Macartney FJ, Shinebourne EA, Tynan M, eds. Pediatric cardiology. New York: Churchill Living-
stone, 1983:1023-56.

4 Caruso G, Cifarelli ABG, Facilome F. Ebstein's malformation of the mitral valve in atrioventricular and ventriculoarterial concordance. Pediatr Cardiol 1987;8:209-10.

5 Leung $M$; Rigby ML, Anderson RH, Wyse RKH, Macartney FJ. Reversed offsetting of the septal attachments of the atrioventricular valves and Ebstein's malformation of the morphologically mitral valve. Br Heart $J$ 1987;57:184-7.

6 Dusmet M, Oberhaensli I, Cox JN. Ebstein's anomaly of the tricuspid and mitral valves in an otherwise normal heart. Br Heart $J$ 1987;58:400-4.

7 Danielson GK, Fuster V. Surgical repair of Ebstein's anomaly. Ann Surg 1982;196:499-504. 